\title{
The Veil of Appearance Phenomenological Inquiries on Husserlian Methodology
}

\author{
Delia Popa \\ Villanova University \\ delia.popa@villanova.edu
}

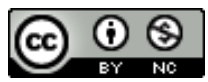

sciendo

Reception date: 23-05-2018

Acceptance date: 12-06-2018

\begin{abstract}
This paper explores the role of appearance in Husserl's theory of knowledge, stressing its importance and its necessity. Far from being an accident that clarity, evidence or reality can evacuate, appearance is constitutive of our experience and of our approach of its grounding principles. In the light of this idea of appearance, the contingent aspects of our lived experience become an expression of the sense-formation process supporting and transforming it. This paper is a contribution to a larger discussion including, among others, Eugen Fink, Michel Henry and Jean-Paul Sartre - about the relationship between phenomenology and ontology, about the nature of our knowledge and our experience of freedom.
\end{abstract}

Keywords: Intentionality, Appearance, Finitude, Experience, Husserl, Fink, Henry

To my students, who teach me to think

The key methodological principle Husserl provided in his early phenomenology, "back to the things themselves (zu den Sachen selbst)" (Husserl, 1901) would be complete non-sense if it did not involve appearance as a problem. Why would there be any interest in rediscovering the "things" our knowledge is built upon, if there wasn't something impeaching us to stay connected to them? Why would we need to go "back", if there wasn't something problematic in the way we learned to move forward? Why would 
Husserl start his phenomenological investigations with such a methodological requirement if he did not know that there is something that only phenomenology can reveal in the midst of epistemological practices that lost track of the very things orienting them? In the following, I will consider appearance as responsible for the distance that keeps us far from we are trying to reach, for the problems arising when we move forward in a field of knowledge and for our feeling of disorientation when engaged in epistemological practices we inherit without questioning.

In a strict, negative, sense, appearance can be understood as obstructing our access to those things that matter or that we seek to clarify, as an obstacle in our search for reality and truth. Misting over any act of apparition (Erscheinung), appearance (Schein) problematically divides it in two: a part that is accessible but uncertain and possibly misleading, and a part that remains inaccessible and yet hopefully real and/or true. Broadly speaking, appearance can be considered as opposed to what can be concretely reached in an experience - its bodily givenness or its "awakening" dimension, that realm of immediate intuition (Anschauung) that Husserlian phenomenology always tried to describe as the most valuable and the most certain.

My claim in this paper is that, with this goal in mind, Husserl struggled with the epistemological problem of appearance in multiple ways and at different stages of his philosophical work. This problem is as old as Husserlian phenomenology itself, arising as a daunting challenge full of a philosophical potential that Husserlian phenomenology slowly made visible. One proof that this was no futile struggle is to be found some thirty years later after the "back to the things themselves" key principle, in the fifth Cartesian Meditations. In regard to the all-embracing Apriori to which every phenomenological explication participates - as for example "a certain, albeit imperfect, evidence contained in the recollection of my own past" - Husserl writes: "The participation in apodicticity appears in the formal law (which is itself apodictic): So much appearance, so much being (soviel Schein, soviel Sein)"1 (Husserl, 1929: 103 [\$46]).

When given a quick (Kantian) look, this formal apodictic law of participation seems to contradict the "back to the things themselves"

\footnotetext{
${ }^{1}$ English translation modified.
} 
methodological principle Husserl proudly claimed in the Introduction to the second volume of the Logical Investigations. How can one wish to go back to the things themselves and in the same time accept that their being is measured by their seeming? How can this formal law accommodate itself with the phenomenological attempt to reach the things themselves? The only way to escape contradiction here is to go beyond the Kantian paradigm where the "formal law" was first enounced, connecting the glorious self-presentation of "things" with the appearance they humbly offer to us. In the phenomenological perspective Husserl is trying to expand on, there is no gap between the two. As far and deep as one would like to go in the realm of what is to be investigated, appearance is the only guide and the only witness for the truth and reality that one can get. Behind this epistemological scene drawn with tools provided by Husserl's theory of intentionality, there is an entire discussion, still timely, still hot, about the nature of the relationship between phenomenology and ontology.

\section{The Origin of the World}

If one considers the Husserlian principle of freedom of presuppositions requesting for each epistemological statement a "comprehensive phenomenological realization" (Husserl, 1901: 263) through adequate intuition, one could think that the main task assigned to phenomenology was to chase any trace of appearance in the theory of knowledge. Husserl aimed indeed at offering new, solid, epistemological basis through the means of an intuition pertaining not only to the sensitive levels of our experience, but also to its "categories" and its essences. Husserlian phenomenology very much operated as a reminder of the basic intuitive (anschaulich) character of our knowledge, seeking to criticize its indirect, vague and exclusively "symbolic" patterns. Husserl suggests we should stay away from those paths of knowledge on which nothing is easier than loosing track of the vivid experience phenomenology is focused on. In this regard, Husserl seems to operate a turning back from Kant to Descartes, affirming the power of an intuition through which an effective access to truth is opened and made available for us. If this were correct, the problem of appearance that Kant himself had analyzed and somehow made famous in his first Critique - and with it, that of the finitude of our knowledge 
- would be simply evacuated in favor if a direct touch on things in their presentation, toward which Husserl seems to orientate his phenomenology.

The ambition to catch the "things themselves" and the restauration of a powerful intuition as means for knowledge are not the only aspects that separate Husserlian phenomenology and Kantian criticism. As Eugen Fink noticed, transcendental phenomenology, as Husserl understood it, also generated a question that could not have emerged within Kantian transcendentalism. This question is about the beginning or the origin of the world. Given the fact that Kant voluntarily restrains knowledge to the frame of a given world of experience, questioning only the conditions of possibility of its experimentation, he cannot really elaborate a view encompassing the genesis of such a world. So, the question that Kantianism cannot ask, made possible by the Husserlian transcendentalism, concerns not the world as such, but the origin of the world (Fink, 1933: 95). Seeking to delineate the borders of what is possibly experienced, Kantian philosophy has already understood the world as problematic. But in Fink's view, Husserlian phenomenology went further: through phenomenological reduction, it found a way to go beyond the limits of the world, exploring the way the world is given to us. This is how the question of the origin of the world arose as a transcendental problem, shedding light to the absolute freedom characterizing transcendental subjectivity (Fink, 1932: 140-149).

However, one should not be confused by the real meaning of this "transgression". As Fink puts it, Husserlian transcendental theory "does not lead outside or away from the world, to an origin which is separate from the world" (Fink, 1933: 99). Rather, the point here is to acknowledge the transcendence of the world and to discover the extend of the belief attaching us to it. In other terms, transcendental phenomenology grasps the world from the standpoint of the transcendental life generating it as the ultimate horizon of our natural existence. This discovery has its condition of possibility in the "awakening of an immeasurable astonishment over the mysteriousness of this state of affairs (Sachlage)" (Fink, 1933: 109) thanks to which we are in the world as animated by an indestructible belief in its existence, a belief that is constitutive for our humanity. There are some interesting consequences to draw for a phenomenological anthropology from the discovery. Fink's argument is not only about the theoretical curiosity one could cultivate about the origin of 
our actual world, but also about our need to have a world in order to be humans. The transcendental subjectivity might enjoy an absolute freedom. But if it does, this freedom appears only in contrast to a necessity that is specifically human: the necessity to belong to a world of experience.

The phenomenological astonishment takes us away from the horizon of the world where Kantian philosophy settled, in order to confront us to its genesis, recognizing it as necessarily correlative to the intentional activity of the transcendental subjectivity - as its sense, conditioning its very existence for us. While Kant proposed a limitative method that remains within the world as it is experienced, Husserl went for a method that has delimitation (Entschränkung) as a purpose. As Fink puts it, Husserlian phenomenology "is a method for going beyond the world by removing limits (Entschränkung über die Welt hinaus)" (Fink, 1933: 119). The origin of the world is the new object of inquiry for phenomenology because the "absolute" at stake is the transcendental life of our consciousness, that bestows its sense. Yet, for Fink, the intentional sense of the world could not be considered as its origin if intentionality were not understood itself as a "productive creation" (Fink, 1933: 134).

Strangely enough, this productive and creative aspect of intentionality does not appear to mere noetic analysis, because the movement of constitution animating the intentional acts, as well as its productive force, cannot be fully grasped at this level of description. One has to understand the intentional activity as sense bestowing in order to reach this aspect, and this understanding is made possible only through the practice of the phenomenological reduction and through the essential clarifications deriving from it. Once this supplementary step is made, the origin of the world appears as transcendental, given the fact that its sense is the unified correlate of the productive life nurturing intentionality. In this perspective, the world is a superficial "stratum" within a transcendental life which flows broader and deeper. Fink speaks about "a stratum which functions as the terminating level of all constitutive processes and which allows the world to arise" (Fink, 1933: 139). Despite of its ultimate character for the natural attitude, that considers it spontaneously as an insuperable canvas, the world proves to be dependent on the transcendental life constituting its sense. Between those borders of the world of our experience in which Kant hoped to enclose transcendental theory, and the absolute life of our 
intentionality, a new area of investigation is accessible where correlations are constantly produced, developed and spread over.

The consequences of this Husserlian "supplement" to Kantian critique are important, as they open a path toward a true transcendental experience - that is an experience of the transcendental as such, as if a new space was made available for description at the deepest levels of our subjective life. Starting with Husserl, one cannot just observe the conditions of possibility of our experience in order to clarify natural experience itself. One has to consider the experience of these conditions themselves, in their specific productivity, as a new valuable epistemic goal. Aren't they the "things themselves" (Sache selbst) Husserl urged us to go back to? Isn't this transcendental experience the one that provides the effectiveness and the concreteness of any possible experience?

\section{Intuition and Finitude: The Problem of Appearance}

The phenomenological overtaking of Kantian transcendentalism goes together with a view on the illegitimate aspirations of reason to transgress the limits of our experience. In this perspective, transcendental phenomenology can be seen as a continuation of that part of Kantian philosophy in which the critical ambition has to put up with a reason inclined to seek for the unlimited. In this sense, Husserlian phenomenology is necessarily concerned by the Kantian problem of the transcendental appearance, to which it is called to provide a new meaning. For Fink, the major dimensions of this problem "dominate the entire constitutive phenomenology" (Fink, 1933: 142), leading to paradoxes that are possibly crucial for the future of the phenomenological research - that is the communicability of the phenomenological discoveries, its expression in a language that is adequate and its relationship to natural human life. Following Fink, the survival of transcendental phenomenology depends on the way we would approach the transcendental appearance affecting these three areas communicability, expression, connection to natural human life - transforming them in territories of thought obscured not only by some accidental aspect of a determined experience, but by a confusion disseminated in its conditions of possibility. How does Husserlian intuitionism accommodate with the problem of the transcendental appearance affecting its conditions of possibility? 
Despite the attempt to consider Husserlian phenomenological project as developing problems initiated by Kantian criticism, the productive aspect of intentionality stressed by Fink in his essay seems to reach somehow behind Kant, toward Descartes, as a revival of an original intuition of which Kant had abandoned the philosophical project in 1772 (Kant, 1772: 312-316). Should one envision the creative aspect of the Husserlian intentionality as a philosophical hybris excluding critical precaution from the field of investigation of transcendental phenomenology? When grounding all form of knowledge in direct intuition considered as a privileged access to the "things themselves", isn't Husserlian phenomenology minimizing the limited conditions of any concrete experience, responsible for its lack of clarity and for its contingent indetermination? When considering closely the Husserlian method, such a hypothesis appears as highly problematic. Husserl never meant to jump blindly "on the other side" of the world, in order to catch a kind a privileged glimpse on its constitution. Rather, he attentively observed the essential laws of our intentional acts, their connections and their correlative senses. This is what makes Husserl's notion of evidence quite different from the one Descartes had, including moments of indetermination and vagueness as stages of its ideal grasp. Moreover,

A real thing, a being having such a sense in an isolated appearance, can in principle only appear "inadequately". It is essentially connected with this, that no rational positing upon such an appearance (that affords things inadequately) can be "definitive", that nothing of the sort can be "incontrovertible", and that any such rational positing in its individual instantiation is not equivalent to straightforwardly positing: "The thing is actual", but is instead equivalent to positing: "It [what appears] is actual" - provided that ongoing experience [Erfahrung] does not bring with it "stronger rational motives" which establish that the original positing is one that, in a wider context, must be "crossed out". Only the appearance (the imperfectly filled out perceptual sense) in and for itself, in its individual instantiation, rationally motivates the positing thereby (Husserl, 1913: 275 [§138]).

This is to say that spatial perception is always inadequate, relying on appearances that do not always confirm the noematic identity pole of the intentional act. In Husserl's words, there are "manifolds of appearances" to 
which every perceived thing prescribes its rule, as a "thing-schema" (Husserl, 1913: 301 [\$150]) that orients the sensations we experience in a unity. Every "external" perception is built through a series of appearances - partial sketches or aspects (Abschattungen) - that provide a limited and always questionable insight into the identity of what we perceive. In itself, the identity of the perceived is only ideally accessible as a unity of all aspects that we apperceive (Husserl, 1929: 50-53 [\$21]), while the act of perception remains attached to parts of the object that can (or possibly cannot) lead us to the perceived itself. There is something like an epistemic fragility in our confrontation with appearances, thanks to which colors and profiles, faces and shapes become confuse and instable. That means that there is always a risk of being misled by appearances, while they are in the same time the only thing we can count on.

Despite of his repeated emphasis on concordance and harmony in the field of our perception, Husserl acknowledges the lack of adequacy that necessarily accompanies the intuitive level of our experience. Far from always confirming the perceptive acts, the sensitive fulfilment is very often a source of disappointment (Enttäuschung), when we notice that there are some discrepancies between the object that we rationally "prescribe" to our experience and the way it is presented within the experience itself, in those incoherent synthesis in which it appears as "being determined otherwise departing from how it corresponded to the original affordance of sense." (Husserl, 1913: 275 [\$138]). These moments of disappointment are far from being seldom. Rather, they seem to guide us, especially when we experience new places and cultures, new languages and landscapes. The discrepancies between our expectations and our effective experience are a source of suffering as well as they are a source of learning and transformation.

So, how are we supposed to reach the "things themselves" (Sache selbst) if we cannot access them otherwise than through partial sketches - that is appearances? Husserl's answer to this question is: appresentation - that is partial presentation of a perceived - is the only way through which we can go "back to the things themselves". The partial sketches - mere appearances that

\footnotetext{
${ }^{2}$ The is a significant difference in German between Sache and Ding. The Husserlian "things themselves" (Sache selbst) should not be confused with the Kantian "things in themselves" (Dinge an sich).
} 
are confirmed or not through the identification process they are engaged in are the means through which things themselves are reached. Among other descriptive moments, the paragraph 150 of the Ideas for a Pure Phenomenology is highly significant as for the consequences of this partial grasp of things perceived:

What we, phenomenologically naive, take as mere facts [Fakta - that a spatial thing always appears to "us humans" with a certain "orientation", for example, oriented in the visual field of sight as above and below, right and left, near and far; that we can see a thing only at a certain "depth" and "distance"; that all changing distances in which it is to be seen are related to an invisible center but as an ideal limit-point quite familiar to us, the center of all orientations of depth, "localized" by us in the head - all these alleged facticities, all these contingencies, of the intuition of space that are alien to the "true", "objective" space, prove to be essential necessities even for slight, empirical particularizations. It is apparent, therefore, that a thing in space of this kind is able to be intuited not merely by us humans but also by God - as the ideal representative of absolute knowledge - only through appearances in which it is and must be given "perspectivally", changing in manifold but determined ways and thereby in changing "orientations" (Husserl, 1913: 301-302 [§150]).

For Husserl, contingent appearances stand for essential features of our experience because every perspective in which an experience is lived is fundamental. The contingent conditions of our perception are "designed" in such a manner that even if the perceiver were the most perfect being, it would still perceive through partial sketches. That is to say that we can experience only through appearances, with no supplementary being hidden behind them to provide certainty. In this regard, for Husserl, there is no such thing as an intuition that would not be shaped by what Levinas interpreted as being the "materiality of sensations" (Levinas, 1965), embracing the specific patterns of our exposure to lived presence.

\section{Intentionality and Phenomenality}

Given its inscription within the factual contingency of the phenomenal world, intentionality strictly understood cannot be considered as an absolute creative 
production as far as it proceeds in a tight solidarity with the world as it appears, as pre-given in its phenomenality. Intentional sense cannot be bestowed independently from phenomenal facticity as we glide along in it, in our everyday life (Popa, 2012). Conversely, the world itself could not appear to us otherwise than as an ultimate correlate of a manifold of acts, all grouped in smaller unities of sense, more or less visible, more or less easy to grasp, that are also interconnected. The world is the encompassing horizon of all our intentional effectuations, whose meaning is constantly maintained through them as the sense of a life-world (Lebenswelt). As Husserl puts it in the manuscripts of Experience and Judgement, the horizon of the world is pregiven in such a way that, if an existent "does not belong to the actual world, it still belongs to a possible world" (Husserl, 1939: 39 [§9]).

This alliance between intentionality and phenomenality is an expression of a process of sense-formation that does not exclude the possibility, developed by Fink in his Sixth Cartesian Meditation ${ }^{3}$, of an absolute freedom within transcendental life. But this freedom cannot appear as a possibility that one can realize in the world of our experience otherwise than though a confrontation with small, contingent, necessities. With Sartre, one can consider this absolute freedom as appearing only negatively (Sartre, 1943), famously contrasting with the objectified frames of our experience as a transparent "sphere of pure spontaneities which are never objects" (Sartre, 1937: 93-96). In this enlarged perspective of a speculative phenomenology, I am tempted to see mundane appearance as a deformed mark or a shadow of an absolute transcendental freedom that cannot find an achieved expression in the world of our current experience. Appearances are like mirrors for a freedom of thought they necessarily fail to reflect in its absoluteness. Instead of reflecting the light or the power coming from the inmost depths of our transcendental life, these blind mirrors refract it into the world of our experience. However, through this failure, something else becomes visible, which is endorsed by each intuitive act.

As an intuitive act enjoying a freedom of modification that perception does not have, imagination reveals the indeterminate aspect of the stream of appearances intentionality is participating to. But imagination does not produce

\footnotetext{
${ }^{3}$ See Moran (2007).
} 
these appearances itself. Rather, its role seems to consist in guiding the freedom of the transcendental life into the material labyrinth of our world of experience. In the life of our imagination, appearances become mobile and fluid, playing with rays of this freedom as they shine within the multi-layered materiality of this world. Far from simply prescribing the limits of our experience, they provide an insight into the complexity of its concreteness. The idea behind such an assumption is once again that transcendental freedom cannot be expressed otherwise than negatively in the intentional system that bestows the sense of our world.

The aim of this speculative excursus is to stress the importance of those traces of finitude Husserl's transcendental phenomenology inherits from Kant. The very idea of merging the phenomenon and the noumenon should not be understood under the umbrella of a new realism that would have finally managed to reach things beyond phenomena. Husserl's project is rather to confer to the phenomena themselves the role of a new center of gravity in his epistemology. Phenomena are the "things" (Sache) we are invited to go back to, as they appear to us, in the fragile givenness of their appearance. The mere absurdity of a background reality separated from phenomenality is denounced by the intentional correlation grounding every possible form of appearance. As Eugen Fink clarified it, "the thing" in transcendental phenomenology is "what is manifested in itself" (Fink, 1933). The self-givenness of the manifestation becomes the new criteria for the effective experience Husserl is trying to grasp.

\section{Appearance and Sense}

Why does Husserl prefer Schein to Erscheinung in his formal apodictic law "as much appearance, as much being" (soviel Schein, soviel Sein) enounced in the fifth Cartesian meditation? This question is legitimate, as an expression of an inquiry about the precise nature of the relationship between appearance (Schein) and appearing (Erscheinung). Following Michel Henry in his book Incarnation, this inquiry necessarily leads to a correction of the Husserlian formal law: instead of measuring our sense of being with mere appearances, one should rather insist on the tight connection between appearing (apparaître) and being (Henry, 2000: 27). This rectification comes as a remedy for the 
confusion coming from the ambiguity of the term "appearance": "By appearance, either we understand the content that appears, or its apparition as such, the appearing (apparaître) itself' (Henry, 2000: 26). Between these two meanings of appearance, the first one seems to be misleading, while the second one is the one Henry choses to explore. Further on, appearing proves to be the condition of possibility of being itself, placing phenomenology as the fundament of ontology, that is: providing its essence.

Henry had already approached the difference between Erscheinung and Schein in his founding work The Essence of the Manifestation where appearance is defined as the alienating horizon of visibility in which the essence of the manifestation - that is, transcendental life - is exposed (Henry, 1963: 222 [\$29]). Interestingly enough, for Henry Erscheinung is the grounding essence of any form of appearance because of its autonomous character - its Selbständigkeit. Yet, this autonomy remains strictly formal if there is no immanent receptivity in which it may be effectively experienced. This is how Henry ends up by grounding the Erscheinung itself in the immanent selfaffectivity receiving it, disconnecting it from the appearance in which it becomes perceptible - in Henry's terms, "visible" or manifested.

In Incarnation, Henry reaffirms his thesis from the Essence of Manifestation: being is certainly not engulfed in random appearances, whereas it is entirely expressed through an appearing (apparaître) whose essence is imperceptible. However, when administering this rectification, Henry minimizes precisely the epistemological role of appearance we so far tried to stress. In the perspective Husserl develops in close relation to Kantian criticism, the phenomenological potential of appearance comes precisely from its mundane exposure and from its contingent fragility. As Levinas would put it, the perceptible aspect of appearance is for Husserl the most convincing proof that our experience is alive (Levinas, 1965). Through its changing modes, appearance is an access to the material concreteness of the world, to its surprising multiplicity given in our sensations. Through its direct touch, phenomenality is impacting us, confirming or rejecting the noetic sense our intentional acts carry. While challenging our senses, appearance is contributing to the process of sense-formation (Sinnbildung) supporting and continuously transforming our experience (Richir, 1991). 
The very idea of phenomenality as having an impact on us is changing the theory of sense as initially presented in the noetic frames of Husserlian intentional analysis: the sense is not only consciously given, but also received; not only prescribed, but also confirmed or "crossed out". Before even grounding an epistemology, the sense is a part of an economy within which it can be rationally bestowed and practically transformed, consciously grasped and sensitively "corrected". There is an adventure of sense and a risk related to its specific modes of appearance as they can harmoniously concord or exclude each other. In the light of this idea of appearance, the contingent aspects of our experience become an expression of the sense-formation process supporting and transforming it.

Interestingly, when Husserl puts appearance in the center of the formal apodictic law enounced in the Cartesian Meditations, he does not refer to any of the two meanings of appearance that Henry is concerned about - that is appearance as a "content" and appearance as the act of appearing - but rather to sensuous appearance as encountered within a given experience. As he clarifies it later in the text, being "is only covered up and falsified thereby and (...) therefore can be asked about, sought, and (by following a predelineated way) found" (Husserl, 1929: 103 [§46]). There is no possible being without an appearance covering it up and falsifying it, because appearance provides the only access to what is. As phenomenology is concerned precisely with the problem of the epistemological access in itself, it necessarily has to consider appearances as having a value in themselves, not only as obstacles to true knowledge, but as conditions for any possible thing to be "asked about, sought, and found". Appearance is the medium of being because being is always given to us in an imprecise and partial manner, through sketches that we grasp as parts of broader unities of sense we have the "task" to fulfill. This is also to say that there is no such thing as rough being, as a condition of possibility that would remain imperceptible to us. Rather, being is always disseminated in a worldly horizon, depending on the sense that is processed through a given experience.

From Husserl to Henry, the essence of phenomenality changed: while in Husserl, this essence can be delivered only through appearances, in Henry's perspective, it is to be found in a totally immanent self-affection that remains imperceptible. On this trajectory from phenomenality to self-affection, transcendental life is thrown out from the realm of sensitive appearances. But 
there might be a way to go back in this journey, if appearance is understood as an expression of the finitude of our experience, as it impacts us each time a settled knowledge meets concrete experience. My claim in this paper would be that through appearance, concrete experience opposes its very own resistance to any meaning that our consciousness catches and articulates. But in the same time, appearance is a part of a broader economy of sense, an economy in which it is processed and transformed in order to be reflected otherwise. There is a call for a diverted attention that comes from our experiences, as they develop further following predelineated ways and in the same time including new, surprising elements.

Confronting us to the limits of an always situated knowledge, appearance also invites us to question the basic motivations of our epistemic inquiries, suggesting that these motivations could be grounded outside any conscious activity, in the depths of an experience that needs it in order to solve its hangups and its intrinsic conflicts. Moreover, appearance could also be seen as a trace of a sense-formation process that includes conscious activity, without ever being totally absorbed in it. This sense-formation process seems to take place in the world of our experience before being referred to us as subjects of a given experience. However, through the disturbing aspect of sensitive appearance, the self-forming sense of an experience calls on us in unique ways that confirm our singularity as responsible recipients (Levinas, 1972).

\section{Bibliography}

FINK, E. (1933 [2000]). «The Phenomenological Philosophy of Edmund Husserl and Contemporary Criticism». In: The Phenomenology of Husserl. Selected Critical and Contemporary Readings. Translated and edited by R. Elveton. Seattle: Noesis Press, 70-139.

- (1932 [1995]). The Sixth Cartesian Meditation. The Idea of a Transcendental Theory of Method with Textual Annotations by Edmund Husserl. Translated by R. Bruzina. Bloomington: Indiana University Press. Henry, M. (2000 [2015]). Incarnation. A Philosophy of Flesh. Evanston: Northwestern University Press.

- (1963 [1973]). The Essence of Manifestation. The Hague: Martinus Nijhoff. HUSSERL, E. (1939 [1973]). Experience and Judgement. Investigations in a 
Genealogy of Logic. Evanston: Northwestern University Press.

- (1913 [2014]). Ideas for a Pure Phenomenology and Phenomenological Philosophy. First Book: General Introduction to Pure Phenomenology, Indianapolis/Cambridge: Hackett Publishing Company.

— (1901 [2000]). Logical Investigations. Vol. I and II. New York: Prometheus Books.

KANT, E. (1772 [2009]). «Letter to Markus Herz». In: E. Watkins (ed.). Kant's Critique of Pure Reason: Background Materials. Cambridge: Cambridge University Press.

LEVINAS, E. (1972 [1987]). «Meaning and Sense». In: Collected Philosophical Papers. Dordrecht: Martinus Nijhoff.

— (1965 [1998]). «Intentionality and Sensation». In: Discovering Existence with Husserl. Evanston: Northwestern University Press, 135-150.

MORAN, D. (2007). «Fink's Speculative Phenomenology: Between Constitution and Transcendence». Research in Phenomenology, 37: 3-31.

POPA, D. (2012). Apparence et réalité. Phénoménologie et psychologie de l'imagination. Hildesheim : Olms.

RICHIR, M. (1991). «La vérité de l'apparence». La part de l'oeil, 7: 229-236.

SARTRE, J.-P. (1943 [1992]), Being and Nothingness. Hazel E. Barnes (Trans.). New York: Washington Square Press.

- (1937 [1957]). The Transcendence of the ego: An Existentialist Theory of Consciousness. Translated by F. Williams and R. Kirkpatrick, Farrar, Strauss and Giroux.

DELIA POPA is Assistant Professor in the Philosophy Department at Villanova University (USA). Her main areas of research are French and German Phenomenology, Social Theory, Aesthetics and Psychopathology. After exploring the relationship between imagination and sense in Husserl's phenomenology in her $\mathrm{PhD}$ (2007), her research focuses on intersubjectivity, selfhood and social norms. Her first book was on Emmanuel Levinas: Les aventures de l'économie subjective et son ouverture à l'altérité (Lumen, 2007). She is the author of Apparence et réalité. Phénoménologie et psychologie de l'imagination (Olms, 2012) and co-editor of Person, Community and Identity(2003), La portée pratique de la phénoménologie. Normativité, critique sociale et psychopathologie (2014) et Approches phénoménologiques de l'inconscient (2015). 